Article

\title{
Towards a Sustainable Spatial Organization of the Energy System: Backcasting Experiences from Austria
}

\author{
Petra Wächter ${ }^{1, *}$, Michael Ornetzeder ${ }^{1}$, Harald Rohracher ${ }^{2}$, Anna Schreuer ${ }^{2}$ and \\ Markus Knoflacher ${ }^{3}$
}

1 Institute of Technology Assessment of the Austrian Academy of Sciences, Strohgasse 45/5, 1030 Vienna, Austria; E-Mail: michael.ornetzeder@oeaw.ac.at

2 Inter-University Research Centre for Technology, Work and Culture, Schlögelgasse 2, 8010 Graz, Austria; E-Mails: rohracher@ifz.tugraz.at (H.R.); schreuer@ifz.tugraz.at (A.S.)

3 Austrian Institute of Technology, Donau-City-Straße 1, 1220 Vienna, Austria;

E-Mail: Markus.Knoflacher@ait.ac.at

* Author to whom correspondence should be addressed; E-Mail: petra.waechter@oeaw.ac.at; Tel.: +43-1-51581-6592; Fax: +43-1-7109883.

Received: 23 December 2011; in revised form: 19 January 2012 / Accepted: 29 January 2012 / Published: 2 February 2012

\begin{abstract}
The transition to a sustainable energy system faces more challenges than a simple replacement of fossil energy sources by renewable ones. Since current structures do not favor sustainable energy generation and use, it is indispensable to change the existing infrastructure. A fundamental change of the energy system also requires re-organizing spatial structures and their respective institutions and governance structures. Especially in Austria, urban sprawl and unsustainable settlement structures are regarded as one of the main developments leading to increased energy demand. One of the aims within the project E-Trans 2050 was to identify socio-economic constellations that are central to the further transformation of the energy system and to focus on actors and their socio-technical framework conditions. Based on a sustainable future vision for the year 2050 a backcasting workshop was conducted to identify necessary steps for the envisaged transition to a more sustainable energy system. The results shed light on the necessary changes for a transformation towards sustainability in the specific Austrian situation. Critical issues are region-specific production of energy and its use, settlement and regional structures and values and role models, which all have a determining influence on energy demand. Combining the knowledge of extensive energy use with available energy resources in spatial planning decisions is a main challenge towards a long term sustainable energy system.
\end{abstract}


Keywords: sustainable energy system; spatial organization; backcasting; energy transition

\section{Introduction}

In many areas of society, developments resulting in increasing energy consumption can be observed. Planning decisions, transport patterns and new forms of domestic energy use are just a few areas where developments from the past have lead to a massive increase in the use of fossil fuels. In many cases it has been complicated to predict and assess long-term impacts on the environment and consequently some development paths with negative environmental effects were initially not regarded as environmentally relevant at the outset. However, the concept of sustainability certainly brought about a deeper discussion on both the evaluation of long-term effects of decision-making and on the possible interdependencies of different policy areas, as well as on arrangements of social norms and interests, technical means, and natural resources. In this paper we aim to pick up on those insights regarding the area of spatial organization of the energy system.

Especially in planning decisions, the impact of spatial organization on society and the environment is a crucial topic. Spatial organization patterns address a multitude of environmental, organizational and social dimensions. As part of the energy system, these dimensions should be explicitly addressed when talking about an energy transition towards more sustainability. Topics like the further dissemination of renewable energy technologies or the relation between energy consumption and the land use implications of infrastructure are obviously linked to spatial planning [1]. Still, the question of how and to what extent spatial organization affects a far-reaching transition in the energy system towards sustainability has not yet been sufficiently explored.

In Austria various social players with different interests and strategies influence decisions in spatial planning. Moreover a number of legal responsibilities in the field of spatial planning lie with local and regional authorities. These and other framework conditions may explain why normative goals of sustainability found in most guidelines for spatial planning have hardly had any effect so far. Although efforts have been made by planning institutions to foster sustainability goals, few policies have had binding effects and their impact has therefore remained marginal. However, on the local and regional level we can find a few exceptional successful cases, like energy self-sufficient municipalities or energy regions mainly based on locally available renewable sources [2].

In this paper we would like to argue that the specific view on energy and spatial organization will require an entirely new composition of policies, bringing together sustainable energy, spatial planning, and land-use regulation issues. Using backcasting as the main research strategy enabled us to discuss and classify policy options without losing track of more radical long-term transition goals. From the specific Austrian context, the paper suggests a number of novel entry points for decision makers, including the establishment of integrated planning structures or the redefinition of existing political-administrational structures. Although most arguments are firmly linked to the Austrian case which constitutes the empirical background of the study findings presented in this paper hopefully could serve as a framework to discuss similar options in other national contexts. 
The paper presents findings from the recently finished project E-Trans 2050 (The project E-Trans 2050 was carried out by three national research-partners, the Inter-University Research Centre for Technology, Work and Culture (lead), the Austrian Institute of Technology, and the Institute of Technology Assessment of the Austrian Academy of Sciences, in the years 2009 and 2010. It was funded by the Climate and Energy Funds and carried out under the programme 'New Energy 2020'.). The main aim of this national project was to achieve a systematic and interactive engagement with socio-technical visions of potential energy futures and to support strategy development at the level of politics, research and companies all involved in the scenario development process. Since we cannot regard a simple substitution of energy sources as a sustainable energy transition, the project tried to address the complex structures of a broadly defined energy system [3]. By evaluating the possible scenarios for the Austrian energy system for the year 2050, the spatial organization of energy production and use has been identified as one of the key fields of action in order to enable more radical changes in the long run. Policy interventions in this crosscutting field have been regarded as central for promoting sustainable transformation pathways of the energy system.

This paper will provide a description of the field of energy and spatial planning. Based on the outcomes of a backcasting workshop, main strategies and policy options will be presented regarding changes in the subfields of renewable energy sources, settlement and regional structures and values and role models. The conclusions reflect on the barriers and opportunities for a transition towards a more sustainable energy system.

The paper is organized as follows: Section 2 gives an overview of critical aspects in spatial planning and organization concerning energy issues, first in general and then specifically from an Austrian context. Section 3 deals with backcasting and experiences made in a workshop, which was held to deepen the understanding of energy issues in spatial planning; whereas Section 4 discusses the results and further explores critical issues identified within the workshop. The conclusions in Section 5 aim to strengthen the need for action and ends with a discussion of further research topics.

\section{Spatial Planning and Regional Energy System}

In recent years, the strong connection between space and energy has gained prominence in the discussions in a mainly regional and local context. With the call for more independence from fossil fuels, regional energy systems are the focus of interest in a number of energy related studies [4-7]. As Walker [8] has already pointed out, energy and land use are tied together by a mutual relationship. On the one hand, the production and utilization of energy has impacts on land use and on the other hand, the use of land determines the consumption of energy in several ways. However, the different sides of this relationship are discussed in different communities whereas a common and integrated discussion focusing on inter-linkages is hard to find. The impacts of energy production on land use are well discussed within the environmental community [9] while the effects of land use, in particular of residential areas, are the focus of the land planning community [10]. The increasing demand for renewable energy sources has given further prominence to the intertwined relationship and it prompts a multidimensional discourse including economic, organizational and social concerns.

Many regions in industrialized countries are covered by disperse and unstructured land use patterns, raising constraints for the reduction of energy consumption over decades. Regional procurement systems 
changed to global supply networks based on the availability of cheap fossil fuels. Solutions to sustainable energy transitions have to consider the long-term dynamics of land use processes and the need to change already existing unsustainable land use structures to sustainable states through a multitude of activities [11].

A major concern relates to settlement structures that lead to increased energy demand due to the prevalence of detached houses in rural areas, and due to missing infrastructure to fulfill basic needs and connection to public transport. Low prices for fossil fuels have provided opportunities for the construction of energy consuming high-rise buildings, causing an increase in energy use in urban areas, especially in high-income countries [12,13]. Living in Anglo-American suburban houses with gardens or in generous flats in city centers are strong and influential lifestyle prototypes for many people all over the world, creating demand for further expansions of energy-intensive types of land use [14].

As so far alternative visions and concrete models are still hard to find on a more general level, in recent years more practical research activities have been forged in this area. One example is the ECOCITY-project [15] aiming at the development of compact, space saving settlement structures enabling an environmentally compatible energy system combined with habitat structures that correspond to the overall objectives for sustainability. The adoption of the urban structure of seven model settlements in Europe resulted in the recommendation concerning community involvement during the planning phase, public spaces with a high value and a great variety of amenities and sustainable transport concepts adapted to the locally different conditions. Further, Filion [16] argues that the strategy of combining multifunctional nodes with high density, transit orientated corridors with residential density would be effective for successful intensification in order to reduce the every day use of cars.

Transitions towards renewable energy supply systems are strongly dependent on the willingness of society to adopt new paradigms. This includes sustainable land use management strategies as well as adaptive sustainable management strategies for renewable energy production. Such requirements are easy to formulate but challenging in realization. It is a big challenge to overcome the barriers of established decision making structures and processes, divergent interests of actors, traditional habits and, last but not least, of systemic lock-in effects.

\subsection{The Austrian Case}

Along with other European countries, Austria is currently increasing efforts towards reducing greenhouse gas emissions, increasing energy efficiency and expanding the deployment of renewable energy technologies. Austria's strengths in the area of renewable energy technologies lie mainly in hydropower and, more recently, biomass. Nevertheless, Austria's overall reliance on fossil fuels still amounts to approximately $75 \%$ of gross domestic consumption and, in spite of a continuous expansion of energy generation from renewables, its share has recently decreased due to an even stronger growth in energy consumption [17]. Especially in the area of transport, reliance on fossil fuels is high and the trend of increasing energy consumption due to rising mobility remains unbroken [18].

As argued in the previous section, a radical restructuring of the Austrian energy system towards sustainability will also require changes in the spatial organization of the energy system. Indeed, the energy strategy recently put forward by the Austrian government in response to the so-called 20-20-20 goals (These goals involve a $20 \%$ share of renewable in the energy mix, a $20 \%$ cut in greenhouse gas 
emissions, and a $20 \%$ cut in energy consumption until 2020, with individual target set for each member state.) agreed upon by the European member states in 2009, has for the first time introduced the term of "spatial planning for energy" (Energieraumplanung) into mainstream policy discourse (see also [19]). It is seen as one of several cross-cutting policy measures and is briefly (and rather vaguely) sketched out as an embedding of energy- and climate related goals into spatial planning, mainly in order to reduce mobility demands [20].

In the following, we will attempt to give a more specific and multifaceted picture of central challenges related to the spatial organization of the Austrian energy system. Table 1 outlines the critical aspects concerning the energy system and spatial planning which will be discussed for the Austrian case. Similar issues may be expected to be relevant in several European countries.

Table 1. Critical aspects concerning the energy system and spatial planning in Austria.

\begin{tabular}{lll}
\hline \multicolumn{1}{c}{ Main aspect } & & \multicolumn{1}{c}{ Critical issues } \\
\hline Land use demands & - & Overall land use demand of renewables \\
of renewables & - & Spatial distribution of renewable energy potentials \\
& - & Land use conflicts between renewables and other land uses \\
& - & Potential land use conflicts between different renewable energy technologies \\
\hline Energy implications of & - & Energy demand for heating dependent on settlement structures (higher \\
settlement structures & & energy demand of detached houses, use of district heating dependent on \\
& dense settlement structures) \\
& - Higher energy demand for infrastructure provision of dispersed settlements \\
& - Energy use for mobility dependent on settlement structures, proximity of \\
& shops, etc.
\end{tabular}

\subsubsection{Land Use Demands and Land Use Conflicts Related to Renewables}

One of the key issues in the spatial organization of the energy system concerns the land-use demands related to the use of different energy technologies. As McDonald and colleagues [21] demonstrate, energy technologies that can contribute to the reduction of greenhouse gas emissions tend to be associated with larger land-use demands. Any transition to more sustainable systems of energy provision will therefore require careful attention to the spatial potentials and limits of the use of renewable energy technologies in a particular country or region. In 2009, the Austrian Conference on Spatial Planning (Österreichische Raumordnungskonferenz, ÖROK), a governmental agency coordinating spatial planning at the national level, put forward a comprehensive survey modeling the spatial potentials of different renewable energy sources in Austria [22]. Results point to some significant untapped potentials, especially in the areas of photovoltaics, solar thermal technology, wind power and geothermal energy. The potential for hydropower and biomass is already comparatively well developed, though some further development options exist. A scenario study, illustrating different possible pathways for the further deployment of renewables in Austria [17] similarly describes a scenario relying strongly on solar thermal technology, photovoltaics and wind power as the most long-term oriented scenario, not least because this would reduce land use demands, as compared to other possible scenarios relying on a radical expansion of energy from biomass. 
In the context of land use demands related to renewables, it also has to be taken into account that the spatial distribution of supply and demand may exhibit quite different patterns. Regional energy concepts attempting to match supply and demand at the regional level have frequently been suggested as a way forward [20,23] and indeed several so-called energy regions in Austria have taken steps in this direction [11]. Detailed models have also been called for, balancing renewable energy potentials and demands at the regional level on the basis of geographic information systems [22]. Nevertheless it may not always be possible to optimize the siting of renewable energy plants according to the availability of natural resources (e.g., wind, solar radiation) and at the same time to ensure a close proximity between energy production and consumption. For example, in Austria the largest share of wind power generation is located in the sparsely populated part of Burgenland and requires investments in the transmission grid to be used in high-consumption areas.

Apart from the spatial distribution of supply and demand one obvious challenge concerning land use demands of renewables concerns (potential) land use conflicts. This issue has recently gained prominence at the global level in the form of the "food versus fuel" controversy, in which extensive use of agricultural land for the production of biofuels has been criticized for competing with land use needs for food production [24]. Apart from an uptake of this global debate, land use conflicts over renewables in Austria have so far mainly taken the form of resistance to hydropower plants that are seen to threaten nature preserves and recreational areas. More recently, some wind farm projects have also triggered local opposition due to concerns over negative impacts on the natural environment, recreational areas and settlement areas (noise, visual impact, etc.). Furthermore, with an increasing use of energy from biomass, conflicts between the use of biomass for energy and for use in wood-based industries (paper industry, pulp industry, etc.) are beginning to emerge [17]. Additional land use conflicts may potentially emerge between different renewable energy technologies (e.g., use of grassland for energy crops or large-scale photovoltaic plants).

\subsubsection{Energy Implications of Settlement Structures and Traffic in Austria}

Dispersed settlement structures and the resulting increase in individualized transport have turned out to be a key driver in energy consumption and greenhouse gas emissions in Austria. Several reasons can be identified for this development:

The past decades have seen a significant trend towards an increase in the number of buildings, apartment sizes and living space. While Austria's population grew by 4.1\% between 1971 and 1991, the number of dwellings increased by $25 \%$ [23]. Moreover, Austria is a country of detached single (or double) family houses, which are favored by $73 \%$ of all Austrians (ibid.). In combination with a trend towards migration from rural areas to the cities (e.g., because of a shift from industry to services which are more often located in urban agglomerations) this has led to an increasing population pressure in urbanized regions and a move of urban population towards suburban areas. These dispersed settlements have various consequences for energy consumption. On the one hand the energy efficiency of single family houses is lower compared to denser settlements and larger buildings. Side effects of this low building density are high costs for infrastructure investments (sewers, roads, electricity, etc.) and the impossibility of supplying such areas with energy-efficient district heating systems. On the other hand sub-urbanization and dispersed settlements increase the volume of traffic. Since post-war 
times the average distance between home and work has risen from two kilometers to 20 to $30 \mathrm{~km} \mathrm{[23].}$ The construction of new roads (along with other drivers) has subsequently led to a vicious circle of a further move towards the urban periphery and further road constructions. Part of this development has also been the increased construction of shopping centers on the outskirts of cities at the cost of grocery shops and convenience stores in the villages and town centers - $51 \%$ of such centers are being built in the periphery of Austrian cities, compared to only 17\% in Germany [25]. Dispersed settlements in the urban periphery and in rural areas not least also mean that public transport services are much less cost-efficient in these areas and have been reduced (or even disbanded) in many places over the past decades. Therefore, it comes at no surprise that traffic-related greenhouse gas emissions rose by $91 \%$ between 1990 and 2005 [18].

An important driver for dispersed settlement structures and a lack of spatial planning for energy and integrated mobility systems lies in the particular institutional set-up of spatial planning competencies in Austria. In principle, spatial development and spatial planning is considered a joint task of the federal level, the Länder (provinces) and municipalities. In practice, the specific forms of distribution of spending and competencies which have evolved historically have worked against well-integrated spatial planning procedures (see [19]). The competence for spatial planning resides for the most part at the level of provinces (leading to different terminologies, priorities and procedures between regions). Municipalities (often very small ones) are responsible for "Regional location development", i.e., local zoning and development concepts. The funding of municipalities largely depends on the number of inhabitants on the one hand and the taxation of companies within their boundaries, which in turn leads to a competition for inhabitants and companies and in consequence to very lax zoning laws to draw more firms and home builders into the township. All in all, these splintered planning competencies along with economic growth and restructuration, changing lifestyles and particular building cultures have led to the dispersion of settlements and growing traffic volumes which now pose a major problem to the reduction of energy demand and greenhouse gas emissions.

As Hamin and Gurran [26], however, point out, there is also a certain trade-off between land-use densification as a measure for climate change mitigation on the one side and the requirements of climate change adaptation on the other, e.g., more open space for stormwater management, urban cooling or species migration.

\section{Backcasting Sustainable Energy Futures}

The aim of the project E-Trans 2050 was to investigate the transition to a more sustainable energy future for Austria. Dealing with such a transition means to be aware of the complex processes of social learning involving a multitude of actors and levels. The system innovations required for profound change involve the reconfiguration of technologies, institutions, social practices as well as cultural norms and values. These societal transformations towards a sustainable energy system are explicitly normative and value-laden and driven by the need to break with a business-as-usual path.

Backcasting is a normative scenario approach proposed for long term changes of twenty to one hundred years addressing changes of human behavior [27]. This is one of the main reasons why backcasting has gained increasing attention in energy and sustainability research [28-34]. In contrast to forecasting approaches, where predictions of a future state are conducted, backcasting scenarios are 
developed according to their desirability of an optimistic and preferable future. As a first step, future goals need to be defined and desirable scenarios have to be developed. Starting from this state in the future, possible paths are examined to reach this desirable future scenario. Therefore, backcasting means working backwards from the desired end-point to the present. Furthermore, backcasting offers a method for exploring the implications of alternative development paths and the values that underlie them [27]. The advantages lie in the possibility to investigate complex problems [35], to address far reaching changes [27], and to outline a common image of the future and make backcasting indispensable for an analysis aiming to identify ways to break with current trends.

The backcasting approach has proven to be useful in identifying development paths under high uncertainty [31] and in emphasizing the long-term impacts of decisions in spatial planning as well as addressing radical changes in energy behavior. Long-term transformations can be visualized and the transition process can be analyzed in depth.

In the project E-Trans 2050 the backcasting procedure started with a highly normative "sustainability scenario" for the Austrian energy system in 2050. This scenario has been tailor-made to cover main aspects at the intersection of energy production and use and spatial organization. It was developed against the background of preceding scenarios, which were formulated at an earlier stage in the project, eight interviews with experts in the areas of spatial planning and development, energy regions, and planning of sustainable energy systems and a literature review (see Table 2). Using this specific vision of the future as a starting point, participants of a one-day backcasting workshop were invited to discuss strategies and necessary milestones that could be helpful in reaching them. Workshop participants were selected on the basis of their specific expertise and institutional background and efforts were made to ensure a diversity of views within the group. The eight participants were representatives of public universities or non-university research institutes (four), a federal agency for environmental issues (one), an association active in the area of environmental issues (one), a private planning company (one), and a private research company (one). Professional backgrounds of the participants included spatial planning, modeling in the area of energy and space, mobility, climate change and its regional impacts, regional development, architecture, and resource-oriented construction. The workshop took place in spring 2010.

Table 2. Long-term vision for sustainability in the field of energy and spatial organization.

\begin{tabular}{ll}
\hline & \multicolumn{1}{c}{ Long-term vision for 2050 } \\
\hline Main aspect & Changes envisioned \\
\hline General data & - Population in Austria: $9.5 \mathrm{~m}(2010: 8.4 \mathrm{~m})$ \\
& - Gross domestic energy consumption: $800 \mathrm{PJ}$ (approx. 50\% less than in 2010) \\
& - Electricity consumption is about $20 \%$ more than in 2010 \\
& - Renewable energy sources cover $90 \%$ of domestic needs \\
\hline Energy prices & $-\mathrm{CO}_{2}$ emissions are $80 \%$ below 1990 levels \\
& - All forms of energy are much more expensive than in 2010 \\
& - Fossil fuels are about twice as expensive as renewable forms of energy \\
& - Percentage of household expenditure on energy mirrors 2010 (around $7 \%)$ \\
& - Social distortion is prevented through the tax system and through transfer \\
& payments
\end{tabular}


Table 2. Cont.

\begin{tabular}{|c|c|}
\hline \multicolumn{2}{|r|}{ Long-term vision for 2050} \\
\hline Main aspect & Changes envisioned \\
\hline Infrastructure & 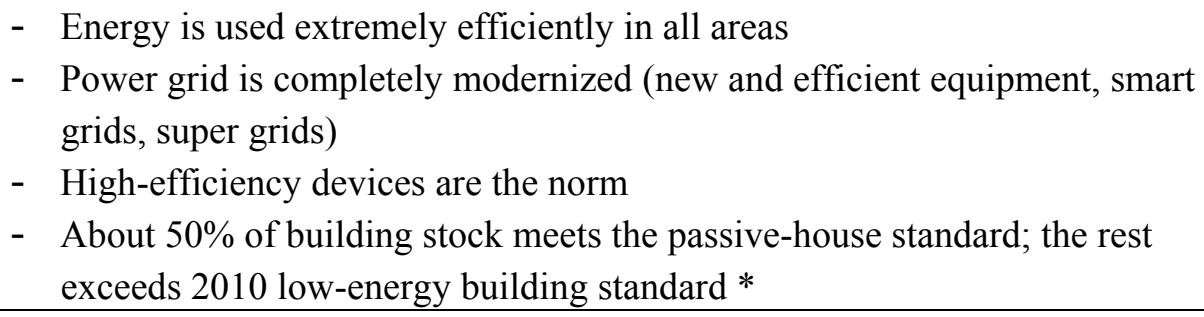 \\
\hline $\begin{array}{l}\text { Spatial } \\
\text { dimensions } \\
\text { of production } \\
\text { and use }\end{array}$ & $\begin{array}{l}\text { - Widespread use of renewable forms of energy } \\
\text { - Use of renewables adapted optimally to local and regional conditions } \\
\text { - } \quad \text { Previously existing capacities are upgraded and slightly expanded } \\
\text { - Consumption and production are located in close proximity } \\
\text { - Widespread use of energy cascading ** }\end{array}$ \\
\hline $\begin{array}{l}\text { Mobility and } \\
\text { transport } \\
\text { infrastructure }\end{array}$ & $\begin{array}{l}\text { - Energy demand for mobility is below } 2010 \text { level } \\
\text { - } \quad \text { More efficient technologies, reduced traffic volume } \\
\text { - Improved public transport system } \\
\text { - } \quad \text { Compact settlement patterns ("short distances") } \\
\text { - } \quad \text { High proportion of bicycle traffic } \\
\text { - } \quad \text { Highly efficient logistics solutions for goods transport }\end{array}$ \\
\hline $\begin{array}{l}\text { Settlement } \\
\text { structures }\end{array}$ & $\begin{array}{l}\text { - Urban centers and medium-sized cities are the main areas for living and } \\
\text { working } \\
\text { - Suburban areas are compact; high quality of life in these neighborhoods } \\
\text { - } \text { Outlying regions are of little economic importance } \\
\text { - Settlement in rural areas has decreased; remaining rural settlements are } \\
\text { populated by elites; more nature reserves than in } 2010\end{array}$ \\
\hline
\end{tabular}

* Statistics show that there were more than 7000 passive houses at the end of 2009 [36]. Approximately two thirds are residential buildings. In 2009, a total of 18470 new buildings had been constructed in Austria [37]. 15.7\% thereof already met passive house standard (2,900 buildings) [36]. It is expected the passive house standard will be obligatory for all new residential building within the next years. The fact that approximately 1 percent of the building stock is replaced per year by new constructions and considering a growing number of retrofits aiming at passive house standard gives the projection for 2050 a realistic basis.

** The term energy cascading is used in referring to a system where a given amount of energy is used on different levels of quality. Co-generation is a simple example for energy cascading; steam (high temperature level) can be used to produce electricity, waste heat (middle or low temperature level) of this process still can be used for industrial of residential needs. In regional energy systems different functions and processes could be linked similar to a cascade.

The proposed long-term vision serves as a widely accepted desirable future state for the year 2050 . The used future vision gives a robust and consistent picture of a state in the future with normative descriptions, concepts and values. The idea is to outline a future state in which a specific type of a sustainable energy system has been reached. Apart from some quite well predictable indicators such as population growth, educated guesses were made at the outset of the process concerning less predictable issues such as the patterns of sustainable energy production and use or sustainability requirements for settlement structures. Prices for all types of energy carriers were assumed to rise but energy demand 
decreases and social distortion is prevented by a balancing tax system and transfer payments. The energy infrastructure is characterized by highly efficient use and powerful electricity grids and a $90 \%$ share of renewables. Regarding the spatial dimension of production and use it was assumed that the use of renewables is adapted optimally to local and regional conditions which mean that locally available forms of renewable energy are employed under best conditions, and consumption and production are located in close proximity. Furthermore, dense settlement structures in suburban areas are combined with the required infrastructure, such as employment opportunities and basic services, leading to a high quality of life. Dispersed settlements in rural areas have decreased and people prefer living in small regional centers that also provide high living standards by fulfilling basic needs within short distances. People living in these centers are not dependent on individualized motorized transport but benefit from an improved public transport system and from the use of bicycles.

The participants of the workshop were first asked to comment on and modify the future vision and to discuss about the most important aspects. In the second part of the workshop, participants were invited to discuss guiding questions concerning opportunities for decision-makers to break with current trends and about essential elements to make the transformation process possible. In order to develop a variety of possible development paths two groups were formed. A more realistic temporal sequence was achieved by answering the crucial question which goals have to be fulfilled in 2030 in order to be able to achieve the desired vision by 2050. The participants proposed and discussed strategies and necessary milestones that could be helpful in reaching the future vision. The biggest challenge in the backcasting process was to think from an imaginary point of time in the future back to the present because our thinking usually takes place in the other direction. The participants were provided with a description of the future vision before the workshop took place but it took some time to until they could sufficiently identify with the vision in order to be able to look back from it. Especially the long time horizon of forty years made the visualization of the transition path difficult. Backcasting requires an abstract way of thinking in an unusual manner which, on the one hand, is a challenge, and on the other hand, it provides the chance to analyze possible solutions by different modes of thinking.

\section{Key Issues on the Transition to Sustainable Energy Structures and Its Spatial Dimension in Austria}

The aim of the backcasting procedure was to identify cross-cutting areas and possibly mutually dependent factors that enforce or hinder the envisaged future vision for the specific situation in Austria. This aim could be achieved on the basis of a brainstorming exercise in two groups focusing on how the envisaged future vision could be reached. The collected items were clustered in certain areas and subsequently prioritized by importance by the participants. The following areas were identified which are critical for a sustainable transition: renewable energy carriers, new and existing settlement structures, regional structures, and values and role models. The development of break-through technologies and different technical-organizational conditions were considered to be of minor importance for reaching the future vision. 


\subsection{Renewable Energy Sources}

As the use of renewable energy sources is steadily growing in Austria, assessments of potentials are available but differ widely in range and in their assessment of related costs. What is still missing are plans focusing on regionally available materials and energy flows to be able to optimise supply and demand and to incorporate this information in planning decisions as early as possible. Austria has a high share of biomass due to large forested areas but estimates consider the potential to be nearly fully exhausted, unless the use of forest resources is organized in a different way. The immense land use is criticized for being a major disadvantage. More potential was seen in the area of solar energy, even in Austria. From the point of spatial planning institutions, the use of solar energy can be optimized by development plans in the construction phase of new buildings, making use of roof areas and facades. Further potential was seen in local and district heating systems in dense settlement areas. As the availability of renewable energy sources is limited, the proximity of production and use is particularly important. Heating plants should be built where renewables are available and users are near in order to avoid long distance transport of e.g., biomass in rural areas and to minimize losses in transport. In the area of electricity, however, the situation is somewhat different. Electricity from renewables is fluctuating and thus requires complementary innovations in the energy system, such as new forms of supply and demand management (e.g., based on smart grids) or new high-power grids connecting the hubs of renewable electricity production at a supra-national level. At the same time, energy regions have an important function as a role model and should be supported and subsidized. The development of big role model projects where the focus lies on integrated solutions concerning settlement structures, mobility and energy should further increase the amount of best-practice examples.

\subsection{New Settlement Structures}

A major part of the discussion focused on the development of sustainable settlement structures. In order to get closer to this target in the next forty years the development of new settlements has to be directed towards new pathways avoiding ongoing urban sprawl and the construction of detached houses in the open country. One of the major structural barriers for energy efficient settlement structures are already granted planning permissions for settlements in the open country. To a large extent these permissions allow the construction of detached houses that usually do not consider any sustainability requirements or do not depend on energy standards, like geographical adjustment, higher degrees of densification or obligatory district heating connections. Institutions such as the Austrian Conference on Spatial Planning have developed a set of sustainability criteria but they merely serve as a recommendation and have not been turned into binding criteria at the national level is still missing and their sustainability guidelines can merely serve as a recommendation. Already granted planning permissions are not likely to be revoked; therefore the participants emphasized the importance of bestpractice examples. New developments of settlements should be compact, built according to ultra-low energy-demand standards, connected to district heating systems, provided with necessary infrastructure and well connected to public transport systems. Apart from sustainability criteria for planning permissions, also new subsidy schemes provided by federal states are an effective tool in stimulating changes in the building sector in the short run (including a shift from subsidies for new construction to 
refurbishment and densification measures). These subsidies have a high impact on a desired polycentric development and could also reduce new constructions by not subsidizing them.

\subsection{Existing Settlement Structures}

The question arises how to deal with unfavorable existing settlements. As the removal of existing buildings was not considered as a realistic option because of expected resistance from local population and authorities, the challenge was rather seen in how to integrate existing settlements into sustainable structures. It is expected that increasing energy prices will lower the attractiveness of dispersed settlements and will possibly lead to more vacancies in settlements in the open country. Most promising instruments are incentives that should enhance compact settlements in already existing regional centers. Settlement structures with a high share of single-family houses should be provided with further infrastructure to be able to organize daily activities in a less energy consuming way such as short distances from housing to work. A main problem in this context is individual motorized traffic which is heavily supported by existing infrastructures. In addition to the changes aiming at a rise in the density of population, it has been argued that existing public transport systems have to be improved in close cooperation with other means of transport in order to solve the "first and last mile problem" in an environmentally sound way, e.g., through the use of electric vehicles or electric bicycles. Moreover improving other local infrastructure as well as offering new services were regarded as an important strategy. Examples for local amenities include a broad variety of shops, health institutions, schools, or recreational facilities. These redensification processes are most promising in suburban areas near larger cities and in smaller regional centers. In regional centers special attention should be paid to a wide variety of businesses and locally available work places leading to less volume of traffic caused by commuters. However, regional centers also have to be connected by high-capacity public transport systems to the main urban centers.

\subsection{New Regional Structures}

In Austria, the room for maneuver in regional planning largely depends on existing politicaladministrative structures. On the one hand the boundaries of administrative units (e.g., municipalities, districts) limit the spatial scope of planning decisions. On the other hand this also narrows down the policy options available to regional governmental institutions. A stronger focus should be placed on the idea of the region, beyond political-administrative regional borders: specific characteristics must be taken into account such as the availability of natural resources and possibilities for their use and availability of infrastructure. Special attention should be paid to renewable energy sources and in the case of thermal energy care should be taken to ensure a high proximity of energy production and use. Regional planning needs to take account of the functions to be fulfilled, such as housing and working, and consider how they can be optimally fulfilled in terms of their related energy use. Depending on the functions that regions have to fulfill, the size of the region may vary from the original political-administrative unit. By defining regional functions region specific strengths and weaknesses can be incorporated into planning processes and additional financial support can serve to enhance such programs. Workshop participants pointed to the successful implementation of 
overarching regional energy structures such as the Austrian region of Eastern Styria where close to 200 municipalities joined to implement a renewable energy region [2].

\subsection{Visions, Role Models and New Practices}

As in most other industrialized countries, traditional role models portrait an unsustainable life-style in Austria: The picture of a happy family with children living in a large single-family house with two big cars in the driveway is the dominant image of a desirable life in the media, in movies and in commercials. Owning a house is related to success and owning a car is associated with freedom and considered as an indispensable need for the organization of daily activities. Structures aiming at less energy demand are definitely not in the focus of these distribution channels. According to the participants, community based use of resources such as community gardening, carpools, bike repair shops demonstrate possible contributions to less energy intensive social practices. Combined with other communal services e.g., shared childcare or care of elderly, dog-walking and some other facets of a neighborhood with high living quality, the basis could be laid for a successful transformation towards new less energy demanding role models on the settlement level. Forerunners like Vienna's car free settlement give some evidence how such new qualities can merge into convincing concepts [38]. At the institutional level, the aim of enhanced societal cooperation instead of ongoing processes of individualization has to be promoted forcefully. One example would be the promotion of owner collectives instead of single house owners that make decisions on a community based level. The provision of information on less energy demanding structures and life styles was seen as another important element in order to break with current trends. Moreover educational programs for children as well as for adults but also regional energy agencies or other information centers in close proximity to people were regarded as a relevant tool in promoting long-term behavioral change towards sustainability.

\subsection{Other Areas}

Further results emphasize the temporal sequence which is necessary to achieve the envisaged future vision. After collecting the most important steps and milestones, the participants were asked to determine which steps are the most urgent ones and have to happen as soon as possible and which ones are more important in the year 2030. Although the participants were divided into two groups both identified the financial equalization scheme between federal, regional and municipal authorities as an immediate leverage for change and recommended that negotiations to reallocate financial resources should start immediately. The reorganization of these financial transfer payments should allow for more flexibility than the current binding budgets for a period of four to six years and payments to municipalities should not only be dependent on population size as it is now. Regions and municipalities could profit from the possibility to devote themselves to special duties, tasks and functions such as the support of renewable energy production or investment in the infrastructure of large-scale demonstration projects. Another issue that has to be tackled as soon as possible aims at the reorganization of housing subsidies schemes that should be abolished for houses outside of regional centers and for single detached houses in general. These subsidies were considered as a powerful tool to promote energy efficient settlement structures and to advance refurbishment projects. Although it was seen as too difficult to implement, participants agreed that the future vision for 2050 could only be 
achieved if spatial planning responsibilities shift from the mainly local and regional level to the federal level and if binding concepts are drawn up to end urban sprawl. Even so, the impact of this administrative reform will need at least 20 to 25 years to take effect.

The workshop participants' explicitly mentioned a number of hindering factors that are likely to hamper necessary transformations towards the envisaged future vision until 2050. The distribution of competencies between spatial planning institutions at the municipal, regional, and federal level was seen as unfavorable for enhancing less energy demanding structures. Planning decisions such as local zoning and development concepts are in the authority of municipalities. What is even more important, several zoning decisions from the past may lead to outcomes inconsistent with political objectives at higher levels or with development plans of other municipalities. The claim for a change in the distribution of competencies is not new but it was seen as unlikely that it will ever happen. Other development routes appear more promising, such as the implementation of large scale infrastructure plans for 30-50 years on a federal level, binding sustainability-criteria in zoning decisions and in landscape planning and long-term local development plans. Some further topics were mentioned but not discussed in detail such as the influence of the building sector and economic interests of financial institutions in the provision of loans for builders of single family detached houses.

Changes of infrastructure and the spatial structure are difficult to implement due to their long life cycles. As it is harder to modify established structures, the best chances of change are seen in the building of new settlements and their related infrastructure, avoiding problematic decisions from the past. The transformation process to more sustainable structures of energy and space was seen as a challenge regarding time, actors and political framework conditions. Furthermore, it was emphasized that even gradual steps of infrastructure change are difficult to achieve and that mutual expectations of experts and decision-makers in the field of energy and spatial planning institutions are sometimes too high.

\section{Conclusions}

In this paper we have focused on spatial organization as a major field of action to influence the transition of the energy system towards more sustainability. It was argued that the energy system and questions of land use are highly interconnected. In the past, inefficient land use patterns and other forms of unfavorable spatial organization have provoked high levels of energy demand. However, alternative forms of spatial organization offer huge opportunities for more radical changes in the energy system. Especially by way of planning new and gradually changing existing infrastructures (regional energy networks, transport and settlement infrastructures) we are able to unfold far-reaching and long-term impacts regarding the production and use of energy.

The results have shown that it would be of decisive importance to improve the coordination of energy policy, spatial planning, and land-use regulation issues on the whole. Among other aspects this would require the establishment of new integrated planning structures at the national and regional levels, the redesign of building subsidy schemes, the closer adjustment of land development plans to energy efficiency and sustainability criteria, and the fostering of increased cooperation across political-administrative borders in the future. In order to support the further expansion of renewable energy resources, it will also be necessary to rebuild regional structures in a way that matches available resources to the existing demand for energy services as closely as possible. It will therefore be important 
to provide regional resource management plans and to develop and implement local and regional energy strategies. Moreover it has been argued that a reallocation of political and legal competences would be essential—one that goes across and beyond the existing political-administrative structures. Finally, a set of recommendations has dealt with the development and implementation of sustainable settlement showcases. Radical new settlement models that combine new social and organizational structures with the latest energy technology and transport infrastructure are not yet available in Austria, but such models were given high priority in the backcasting workshop as a first step towards a more sustainable energy system. In order to get these models to work in practice, actors from research, technology development, planning, architectural, and political fields must work together in close cooperation with investors and on-site users. Hence it is necessary to set up appropriate developer and participation models and to establish the necessary policies and frameworks. The implementation of innovative settlement showcases would be an important first step towards a more sustainable energy future and could open up much-needed opportunities for social and technical learning.

Apart from these short-term opportunities, the discussions in the workshop has also pointed to some of the limits to structural changes - at least in the Austrian context. In two fields it seems very unlikely that strategies and policies will be successful in the near future: One is the change in the distribution of competencies in spatial planning institutions on a federal, regional and local level and the other is a rearrangement of unsustainable settlement structures. Instead of those top down oriented strategies, it was argued that social engagement and bottom-up processes should be encouraged and established. The spatial planning authorities could be re-organized and new incentive structures for local authorities should be established in order to make ecologically more favorable planning decisions.

In terms of spatial planning, a planning period of forty years is not long. Changes in spatial organization, even if they are implemented today, would need a time span of at least twenty years in order to produce any effects and allow us to profit from more sustainable regions including energy production and transport and more sustainable planning decisions. The critical issues discussed in this paper reflect the need for action and strengthen the importance of linking energy and space.

\section{Acknowledgments}

The authors want to thank the Austrian Climate and Energy Fund for providing financial support to conduct the project E-Trans 2050 on which the results are based. Further, special thanks go to all backcasting-workshops participants for their valuable comments and contributions. The authors are grateful to two anonymous reviewers whose valuable comments helped to improve the quality of the paper.

\section{Conflict of Interest}

The authors declare no conflict of interest.

\section{References}

1. Stremke, S.; Koh, J. Ecological concepts and strategies with relevance to energy-conscious spatial planning and design. Environ. Plan. B 2010, 37, 518-532. 
2. Späth, P.; Rohracher, R. "Energy regions": The transformative power of regional discourses on socio-technical futures. Res. Policy 2010, 39, 449-458.

3. Dale, V.H.; Efroymson, R.A.; Kline, K.L. The land use-climate change-energy nexus. Landsc. Ecol. 2011, 26, 755-773.

4. Graymore, M.; Sipe, N.G.; Rickson, R.E. Regional sustainability: How useful are current tools of sustainability assessment at the regional scale? Ecol. Econ. 2008, 67, 362-372.

5. Walz, A.; Lardelli, C.; Behrendt, H.; Grêt-Regamey, A.; Lundström, C.; Kytzia, S.; Bebi, P. Participatory scenario analysis for integrated regional modelling. Landsc. Urban Plan. 2007, 81, 114-131.

6. Madlehner, R.; Kowalski, K.; Stagl, S. New ways of integrated appraisal of national energy scenarios: The case of renewable energy use in Austria. Energy Policy 2007, 35, 6060-6074.

7. Bohunovsky, L.; Madlener, R.; Omann, I.; Bruckner, M.; Stagl, S. Die lokale Energienutzung der Zukunft-Integrierte Nachhaltigkeitsbewertung von lokalen Energieszenarien. Ökologisches Wirtsch. 2007, 2, 47-50.

8. Walker, G. Energy, land use and renewables. A changing agenda. Land Use Policy 1995, 12, 3-6.

9. Hoogwijk, M.; Faaij, A.; Eickhout, B.; de Vries, B.; Turkenburg, W. Potential of biomass energy out of 2100, for four IPCC SRES land-use scenarios. Biomass Bioenergy 2005, 29, 225-257.

10. Nolon, J.R. Land Use for Energy Conservation and Sustainable Development: A New Path Toward Climate Change Mitigation; Pace Law Faculty Publication: New York, NY, USA, 2011.

11. Späth, P.; Koblmüller, M.; Kubeczko, K.; Faber, F.; Bärnthaler, J.; Bergmann, H.; Luttenberger, C.; Breisler, A. Energieregionen: Wirksame Leitbildprozesse und Netzwerke zur regionalen Gestaltung sozio-technischen Wandels; Energiesysteme der Zukunft: Vienna, Austria, 2007.

12. Rong, F. Residential Energy Use. Ph.D. Thesis, University of Maryland, College Park, MD, USA, 2006.

13. Poumanyvong, P.; Kaneko, S. Does urbanization lead to less energy use and lower $\mathrm{CO}_{2}$ emissions? A cross-country analysis. Ecol. Econ. 2010, 70, 434-444.

14. Bin, S.; Dowlatabadi, H. Consumer lifestyle approach to us energy use and the related $\mathrm{CO}_{2}$ emissions. Energy Policy 2005, 33, 197-208.

15. Gaffron, P.; Huismans, G.; Skala, F. Ecocity-A Better Place to Live; Facultas Verlags- und Buchhandels AG: Vienna, Austria, 2005.

16. Filion, P. Suburban mixed-use centres and urban dispersion: What difference do they make? Environ. Plan. A 2001, 33, 141-160.

17. Hinterberger, F.; Stocker, A.; Bohunovsky, L.; Kowalski, K.; Wolter, M.I.; Großmann, A.; Madlener, R. Erneuerbare Energie in Österreich: Modellierung möglicher Entwicklungsszenarien bis 2020; Energiesysteme der Zukunft: Vienna, Austria, 2009.

18. Umweltbundesamt. Austria's Annual Greenhouse Gas Inventory 1990-2005; Umweltbundesamt: Vienna, Austria, 2007.

19. Austrian Conference for Spatial Development (ÖROK). Austrian Spatial Development Concept 2011; ÖROK: Vienna, Austria, 2011.

20. BMWFJ; BMLFUW. Energie-Strategie Österreich: Maßnahmenvorschläge; BMWFJ: Vienna, Austria, 2010. 
21. McDonald, R.I.; Fargione, J.; Kiesecker, J.; Miller, W.M.; Powell, J. Energy sprawl or energy efficiency: Climate policy impacts on natural habitat for the united states of america. PLoS One 2009, 4, doi:10.1371/journal.pone.0006802.

22. Austrian Conference for Spatial Development (ÖROK). Energie und Raumentwicklung-Räumliche Potenziale Erneuerbarer Energieträger; ÖROK: Vienna, Austria, 2009.

23. Kanatschnig, D.; Weber, G. Nachhaltige Raumentwicklung in Österreich; Institut für Raumplanung und Ländliche Neuordnung: Vienna, Austria, 1998.

24. Zah, R.; Ruddy, T.F. International trade in biofuels: An introduction to the special issue. J. Clean. Prod. 2009, 17, S1-S3.

25. VCÖ. Einfluss der Raumordnung auf die Verkehrsentwicklung; VCÖ: Vienna, Austria, 2007.

26. Hamin, E.M.; Gurran, N. Urban form and climate change: Balancing adaptation and mitigation in the US. And australia. Habitat Int. 2009, 33, 238-245.

27. Robinson, J.B. Futures under glass - A recipe for people who hate to predict. Futures 1990, 22, 820-842.

28. Robinson, J.B.; Burch, S.; Talwar, S.; O’Shea, M.; Walsh, M. Envisioning sustainability: Recent progress in the use of participatory backcasting approaches for sustainability research. Technol. Forecast. Soc. Chang. 2011, 78, 756-768.

29. Kok, K.; van Vliet, M.; Bärlund, I.; Dubel, A.; Sendzimir, J. Combining participative backcasting and exporatory scenario development: Experiences from the scenes project. Technol. Forecast. Soc. Chang. 2011, 78, 835-851.

30. Carlsson-Kanyama, A.; Dreborg, K.H.; Moll, H.C.; Padovan, D. Participative backcasting: A tool for involving stakeholders in local sustainability planning. Futures 2008, 40, 34-46.

31. Quist, J. Backcasting for a Sustainable Future: The Impact after 10 Years; Eburon Academic Publishers: Delft, The Netherlands, 2007.

32. Berkhout, F.; Hertin, J.; Jordan, A. Socio-economic futures in climate change impact assessment: Using scenarios as "learning machines". Glob. Environ. Chang. 2002, 12, 83-95.

33. Anderson, K. Reconciling the electricity industry with sustainable development: BackcastingA strategic alternative. Futures 2001, 33, 607-623.

34. Robèrt, K.H. Tools and concepts for sustainable development, how do they relate to a general framework for sustainable development, and to each other? J. Clean. Prod. 2000, 8, 243-254.

35. Dreborg, K.H. Essence of backcasting. Futures 1996, 28, 813-828.

36. Lang, G. Internationale Passivhaus Datenbank: 1. Dokumentationsperiode 2007-2009; Federal Ministry for Transport, Innovation and Technology: Vienna, Austria, 2009.

37. STATISTIK AUSTRIA, Adress-, Gebäude- und Wohnungsregister. Available online: www.statistik.at/web_de/statistiken/wohnen_und_gebaeude/errichtung_von_gebaeuden_und_woh nungen/fertigstellungen/026021.html (accessed on 16 January 2012).

38. Ornetzeder, M.; Hertwich, E.; Hubacek, K.; Korytarova, K.; Hass, W. The environmental effect of car-free housing: A case in Vienna. Ecol. Econ. 2007, 65, 516-530.

(C) 2012 by the authors; licensee MDPI, Basel, Switzerland. This article is an open access article distributed under the terms and conditions of the Creative Commons Attribution license (http://creativecommons.org/licenses/by/3.0/). 